\title{
RNA Silencing Pathways in Plants
}

\author{
A.J. HerR AND D.C. Baulcombe \\ The Sainsbury Laboratory, Norwich NR4 7UH, United Kingdom
}

In one of the first described examples of RNA silencing there was coordinate suppression (cosuppression) of a transgene and an endogenous gene. Petunia plants with a flower pigment transgene (chalcone synthase [CS]) had white flowers because the transgene and the endogenous gene were silenced (Napoli et al. 1990; van der Krol et al. 1990). There was no reduction in the transcription of the endogenous gene and it seemed likely that an RNA turnover mechanism was specifically targeted at CS RNA (van Blokland et al. 1994). In this and in other cosuppression systems, the target RNA had a nucleotide sequence that was identical to the transgene. When these findings were first described, it was not understood how such cosuppression could have such sequence specificity. However, based on discoveries in animal and plant systems, it is now apparent that cosuppression is an RNA silencing process (Baulcombe 2004) in which RNA and DNA sequences are targeted specifically depending on the nucleotide sequence.

The defining feature of RNA silencing is the involvement of long double-stranded (ds) RNA, which is processed by an RNAse III-type enzyme (Dicer) into short (21-25-nucleotide) interfering (si) RNAs that initially exist in a ds form with two nucleotide overhangs at the 3 ' ends. These short RNAs are separated into a singlestranded (ss) form that guides effector complexes of silencing to a target RNA by Watson-Crick base pairing. Proteins of the Argonaute class are key components of these effector complexes. They bind siRNAs (Song et al. 2003; Yan et al. 2003; Ma et al. 2004) and are the "Slicer" ribonuclease that degrades the target RNA (Liu et al. 2004; Meister et al. 2004; Rand et al. 2004).

In the petunia cosuppression system, the dsRNA and siRNA were derived from the transgene and the target RNAs were the CS RNAs from either the transgene or the endogenous gene (Stam et al. 2000). A similar process is also involved in silencing of endogenous RNAs. In this natural mechanism Dicer cleaves noncoding RNAs with partially ds regions into short (21-24-nucleotide) regulatory RNAs known as microRNAs (miRNAs). In plants the miRNAs are targeted to mRNAs of proteins affecting development and responses to environmental stimuli (Bartel 2004). Transcription factors are heavily represented in the subset of miRNAs that are conserved in distantly related plants (Jones-Rhoades and Bartel 2004). However, less is known about more recently evolved miRNAs and their targets (Allen et al. 2004).

This basic Dicer-Slicer pathway accounts for the sequence specificity of RNA silencing, but it does not ex- plain why silencing of CS was not uniform in certain petunia plants with cosuppression. Occasionally these plants produced colored flowers with spots and streaks of CS silencing (Jorgensen et al. 1995). Moreover, the basic pathway does not explain the late stages of RNA virus-induced transgene silencing. The early stages of this process can be understood in terms of the basic pathway: A virus vector with its transgene-specific insert is a source of dsRNA that is processed by Dicer into siRNA and, within two or three weeks, the virus and transgene RNA are reduced to undetectable levels by the silencing mechanism (Ruiz et al. 1998). However, in the later stages, the transgene itself becomes the source of the siRNAs and the silencing persists throughout the life of the plant, although not into the next generation (Ruiz et al. 1998). There must be epigenetic and other mechanisms that could account for the instability of cosuppression and the persistence of virus-induced transgene RNA silencing.

In this paper, we describe variations on the basic silencing pathway and their implications for understanding of the mechanisms and natural roles of RNA silencing. The emerging picture is of a network of RNA silencing pathways. Some of these pathways involve DNA and chromatin modification. There may also be feedback loops and positive or negative interactions between different pathways.

\section{MOLECULAR ANALYSIS OF POSTTRANSCRIPTIONAL GENE SILENCING}

Our laboratory originally set up two different transgene silencing systems that were intended to mimic cosuppression in petunia. The first system was in Nicotiana benthamiana and we infiltrated the lower leaves of these plants with an Agrobacterium culture to initiate silencing. These bacterial cells had a silencer GFP transgene in their Ti plasmid that would have been transferred into plant cells in the infiltrated leaves (Voinnet and Baulcombe 1997). A GFP transgene in the genome of the N. benthamiana served as a reporter of the silencer activity.

The silencer and reporter GFP transgenes were cosuppressed, as expected, in the infiltrated leaves of these plants. However, there was also silencing of the GFP reporter in a ring of cells around the infiltrated region and in upper parts of the plant (Fig. 1) (Voinnet and Baulcombe 1997; Himber et al. 2003). It seems, as found independently by Vaucheret and colleagues (Palauqui et al. 1997), that a mobile silencing signal moves between cells and through the vascular system of the plant. Systemic silencing is nucleotide sequence-specific and it is 


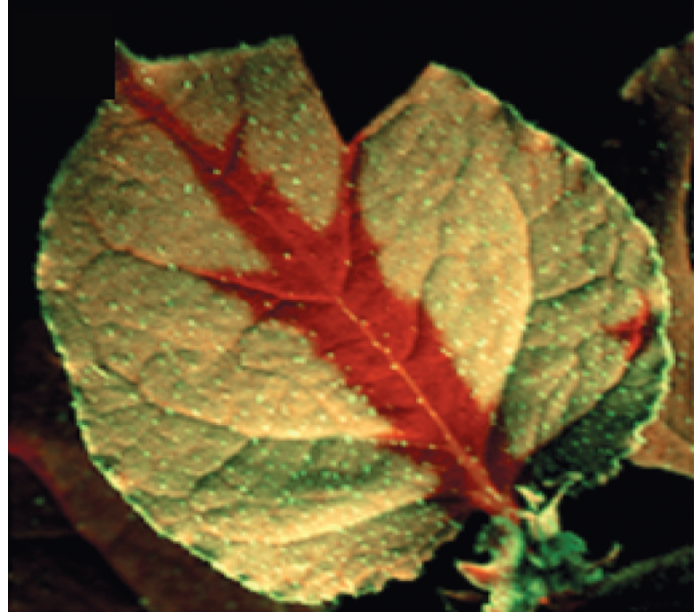

Figure 1. Systemic silencing in Nicotiana benthamiana. This upper leaf was imaged under UV light 11 days after silencing had been initiated by transient expression of a GFP transgene on a lower leaf. The green areas indicate parts of the leaf where GFP is expressed and the red areas indicate loss of GFP due to spread of a silencing signal out of the veins.

likely that RNA intermediates - dsRNA or siRNA — are the signal, either as naked RNA or in association with proteins. The spots and streaks of CS cosuppression in transgenic petunias may be due to movement of a silencing signal (Jorgensen et al. 1995).

RNA silencing also spreads systemically in Caenorhabditis elegans but it is unlikely that the transport mechanism is the same as in plants because the signal crosses a membrane when it enters the animal and requires a putative RNA transporter protein (Feinberg and Hunter 2003). This type of protein would not be required in plants because most of the cells, including the phloem cells of the vascular system, are interconnected through plasmodesmatal channels that are a continuation of the endoplasmic reticulum (Haywood et al. 2002).

The $N$. benthamiana system also allowed us to investigate the specificity determinant of RNA silencing. It seemed likely, to explain the nucleotide sequence specificity and posttranscriptional basis of the silencing process, that this determinant would be an antisense RNA and that it would be present only after induction of silencing by transient expression of the silencer GFP transgene. Andrew Hamilton had first seen evidence for such antisense RNAs in transgenic tomatoes that were undergoing cosuppression of the polygalacturonase fruit ripening gene: They were the short RNAs that are now referred to as siRNAs. However, his finding that GFP siRNAs correlated with systemic GFP silencing in N. benthamiana provided some of the first confirmation that they were functionally important (Fig. 2) (Hamilton and Baulcombe 1999; Hamilton et al. 2002).

\section{GENETIC ANALYSIS OF POSTTRANSCRIPTIONAL GENE SILENCING}

Our second silencing system also involved a GFP reporter and was designed so that we could screen for loss of silencing mutants in Arabidopsis (Dalmay et al. 2000).

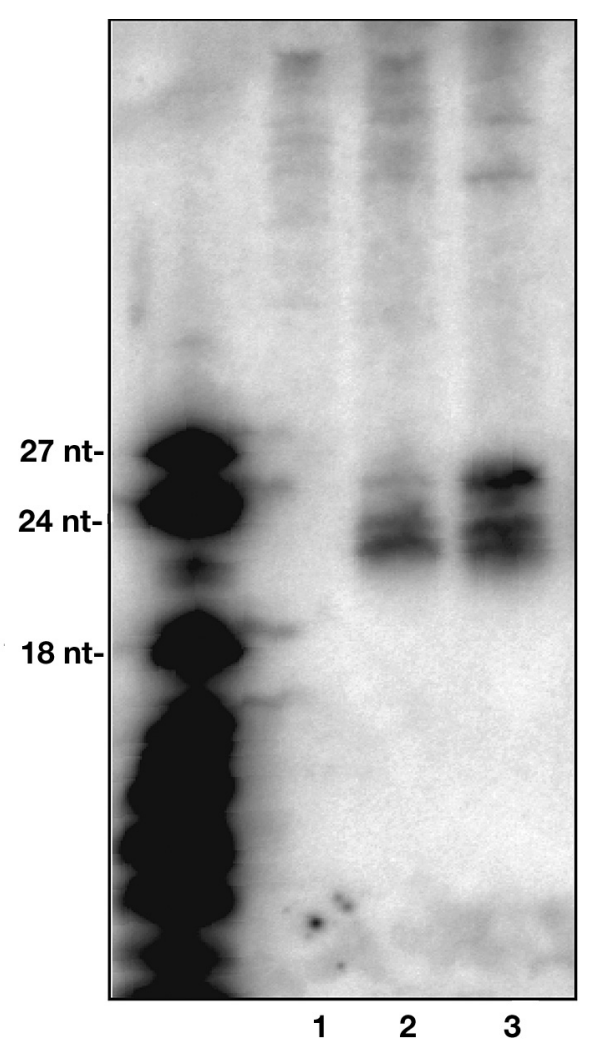

Figure 2. siRNA. The autoradiograph shows a northern blot of GFP siRNA extracted from GFP transgenic $N$. benthamiana that was either not silenced (lane 1 ) or silenced (lanes 2 and 3 ). The siRNAs migrate in 24-nucleotide and 21/22-nucleotide size classes.

The first characterized locus, formerly $S D E 1 / S G S 2$, is now referred to as $R D R 6$, because it encodes one of a family of RNA-dependent RNA polymerase (RDR) homologs. These RDRs are required for RNA silencing in C. elegans (Smardon et al. 2000; Sijen et al. 2001) and fungi (Cogoni and Macino 1999; Volpe et al. 2002), as well as in Arabidopsis (Dalmay et al. 2000; Mourrain et al. 2000; Xie et al. 2004). They share a common sequence motif that is distantly related to the catalytic domain of DNA-dependent RNA polymerases (Iyer et al. 2003) and it is therefore likely that they are an ancient group of proteins although they do not have homologs in the genomes of mammals and Drosophila. Other mutants in our screen implicated a putative RNA helicase SDE3 and a protein of unknown function (SGS2) that had previously been described (Mourrain et al. 2000). The sde5 locus (T. Dalmay and D.C. Baulcombe, unpubl.) also encodes a protein of unknown function and $s d e 4$ is discussed below.

A likely role of the RDR proteins in RNA silencing is in the synthesis of a dsRNA from an ss template (Fig. $3 \mathrm{~A})$. It seems that the RDR is able to use certain RNAs as a template because it somehow recognizes them as being "aberrant." Consistent with this idea, in vitro assays with Neurospora crassa (Makeyev and Bamford 2002) and tomato enzymes (Schiebel et al. 1993) indicate de novo synthesis of dsRNA on a ssRNA template that may recapitulate this role of RDR proteins. Similarly, in wheat germ extracts, an ssRNA can be copied into complemen- 

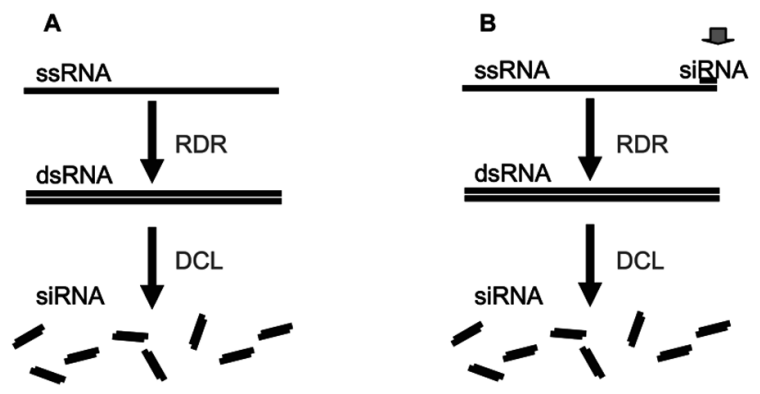

Figure 3. RDR pathways. (A) An RDR protein generates dsRNA on a ssRNA template and DCL Dicer produces primary siRNA. (B) The RDR proteins may also use the primary siRNA as a primer so that dsRNA and siRNA production is accelerated.

tary RNA by an unidentified enzyme that, presumably, is an RDR (Tang et al. 2002). An indication of how an RNA might be recognized as "aberrant" is from the finding that RNA without a 5' cap gives enhanced RDR-dependent silencing (Gazzani et al. 2004). Factors that bind the 5' cap stimulate ribosome loading in concert with factors bound to the polyA tail (Sachs and Varani 2000). In the absence of the interaction between the $5^{\prime}$ and $3^{\prime}$ ends, the RNA would be depleted of ribosomes and perhaps more accessible to the RDR.

The RDR proteins may also have a second mode of action in which RDR-mediated synthesis of dsRNA is primed by an siRNA (Fig. 3B). The resulting dsRNA would then be processed by Dicer into secondary siRNAs that, in turn, are primers for additional cycles of siRNA synthesis. Consistent with this mechanism, the QDE1 RDR protein from $N$. crassa incorporates a labeled 20nucleotide antisense RNA into the complementary strand of an ssRNA in vitro (Makeyev and Bamford 2002). There is also indirect genetic evidence for primed synthesis from silencing systems in C. elegans and Arabidopsis thaliana that are initiated by primary siRNAs corresponding to part of the target RNA. The secondary siRNAs that eventually accumulate in these systems do not correspond only to the primary siRNA region; they also correspond to the adjacent regions of the target RNA (Sijen et al. 2001; Vaistij et al. 2002). Production of these secondary siRNAs is dependent on RDR proteins and, in C. elegans, they are from the $5^{\prime}$ side of the primary siRNA (relative to the template RNA), as would be predicted by the primer model. In A. thaliana and N. benthamiana it is likely that the primary siRNAs use both sense and antisense RNAs as a template because the secondary siRNAs are from both sides (Voinnet et al. 1998; Vaistij et al. 2002). There are many antisense transcripts from the $A$. thaliana genome (Yamada et al. 2003) and so there would be ample opportunity for this bidirectional synthesis of secondary siRNAs.

\section{RNA SILENCING AND SUSCEPTIBILITY TO PLANT VIRUSES}

Some of the first detailed analyses of RNA silencing were with plants that were carrying viral transgenes
(Lindbo et al. 1993; Longstaff et al. 1993). There was cosuppression in these plants of the transgene and the corresponding viral gene so that the plants were resistant against the transgene-specific virus but not against related strains. In some instances, this resistance was so strong that the plants were completely immune and it seemed possible that the transgenic plants were recapitulating a natural resistance mechanism that was activated in virus-infected plants. Subsequently, a series of analyses confirmed this interpretation through the findings that viruses in nontransgenic plants can activate an RNA-mediated and sequence-specific resistance mechanism that was associated with virus-specific siRNAs (Ratcliff et al. 1997; Hamilton and Baulcombe 1999). Also consistent with this finding was the discovery that viruses encode suppressor proteins of the RNA silencing pathway (Anandalakshmi et al. 1998; Brigneti et al. 1998; Kasschau and Carrington 1998). These proteins represent the counterdefense system that would inevitably evolve in response to the defense role of silencing. The link of RNA silencing and virus resistance was further reinforced by the finding that loss of function in RDR1 and RDR6 results in hypersusceptibility to virus infection (Mourrain et al. 2000; Xie et al. 2001).

Our analysis of an RNA virus (potato virus X-PVX) indicates a link between the virus defense role of RNA silencing, the silencing signal, and the role of RDR6. We found that suppression of silencing by the PVX p25 is necessary for cell to cell movement of the virus (Voinnet et al. 2000; E. Bayne and D.C. Baulcombe, unpubl.) and that RDR6 is necessary to prevent invasion of the meristem by the virus (F. Schwach and D.C. Baulcombe, unpubl.). To explain these findings we propose that the RNA signal of silencing can spread through the plant either with or ahead of the virus and that, directly or indirectly, it can silence the viral RNA. In a wild-type plant with a wild-type virus this signal would be normally suppressed but not completely eliminated by the p 25 silencing suppressor. The virus would move freely out of the initially infected cell because this low level of signal would be less abundant than the viral RNA. If the p 25 suppressor is deleted, however, the signal would be much more abundant and, as observed, the virus would be unable to spread out of the initially infected cells.

Our model further proposes that, in the growing point of the plant including the meristem, the signal blocks virus accumulation through a mechanism that is dependent on RDR6. A plausible scenario for this process requires that the systemic silencing signal is an siRNA. It would enter the meristematic cells with the viral RNA and, using this RNA as template, would prime RDR6-mediated synthesis of secondary siRNAs as described above (Fig. 3B). This secondary siRNA would have an antiviral effect in the meristem because, after several rounds of RDR6-mediated amplification, it would be more abundant than the viral RNA.

A similar model may also account for the observations of S.A. Wingard at the Virginia Experimental Station in 1928. He described infected tobacco plants in which only the initially infected leaves were necrotic and diseased due to tobacco ringspot virus (Wingard 1928). The upper 
leaves had somehow become specifically immune to the virus and, consequently, were asymptomatic and resistant to secondary infection. We now know that recovery from virus disease involves RNA silencing that is targeted specifically at the viral RNA (Covey et al. 1997; Ratcliff et al. 1997) and, as the immunity is effective in newly developing leaves, it is likely that it is established in the meristem.

In animals the NS1 and E3L proteins of influenza and vaccinia viruses ( $\mathrm{Li}$ et al. 2004) and the B2 protein of flock house mosaic virus (Li et al. 2002) have silencing suppressor activity. In addition there are five different miRNAs in Epstein-Barr-virus-infected mammalian cells corresponding to inverted repeat regions in the viral genome (Pfeffer et al. 2004). However, this is the only report of siRNA or miRNAs corresponding to mammalian viruses and the silencing suppressor activity of the influenza and vaccinia virus proteins could be a side effect of their dsRNA binding activity (Lichner et al. 2003). Thus, based on current evidence, it seems unlikely that RNA silencing in mammals is a general defense against viruses as it is in plants. Perhaps it is effective against a subset of mammalian viruses or is an antiviral defense in embryonic or other cells in which the systems of innate and humoral immunity are not effective.

\section{RNA-MEDIATED TRANSCRIPTIONAL SILENCING}

RNA silencing in plants is often associated with changes to the methylation of histones and DNA at the target gene locus (Mathieu and Bender 2004). The basic mechanism of RNA silencing, as described above, does not explain a link with chromatin/DNA modification. However, it has been known since 1994 that there is the potential for such a link because DNA methylation in plants can be directed by RNA (Wassenegger et al. 1994). The first described example of RNA-directed DNA methylation (RdDM) involved plants carrying a transgene derived from the genome of a noncoding RNA pathogen - a viroid. The transgene DNA was not methylated in noninfected plants but, after viroid inoculation, it was methylated specifically in the regions corresponding to the viroid RNA (Wassenegger et al. 1994).

The link of RdDM and RNA silencing pathway was subsequently confirmed from the demonstration that transcribed inverted repeat transgenes could target DNA methylation and transcriptional silencing if they corresponded to a promoter sequence (Mette et al. 2000; Aufsatz et al. 2002a). The link with RNA silencing correlated with the presence of siRNA derived by Dicer-mediated processing of the foldback transcripts of the inverted repeat RNA. Similarly, when an RNA virus was engineered to carry a transgene promoter sequence as RNA, the transgene was silenced in the infected plant and the promoter was methylated. In this example, the promoter methylation and silencing persisted in the progeny of the infected plant, although the virus was not transmitted between generations (Jones et al. 1999).

Further evidence for a link of RdDM and RNA silenc-

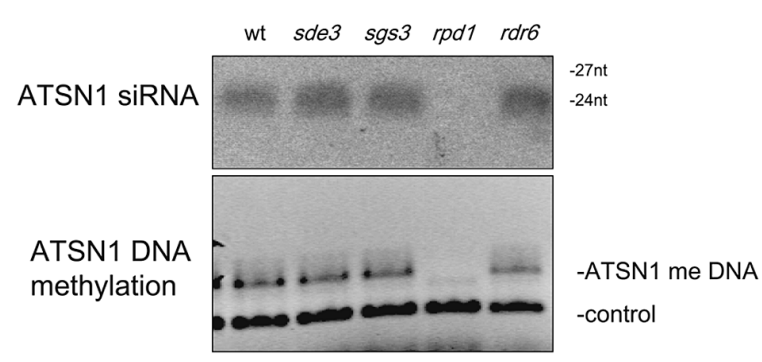

Figure 4. The effect of mutations on endogenous siRNA AtSN1 and DNA methylation. (Upper panel) An siRNA northern blot probed for AtSN1. The nrpdla(sde4) mutant lacks this siRNA. (Lower panel) Polymerase chain reaction (PCR) analysis of AtSN1 DNA methylation in which the slower migrating PCR product corresponds to the methylated DNA that is absent in the rpdl(sde4) mutant.

ing was from analysis of an Arabidopsis mutant (nrpdla(sde4)) with a partial loss of transgene RNA silencing phenotype. This mutant also lacked a 24-nucleotide class of endogenous siRNAs including those corresponding to a short interspersed nucleotide element (SINE) AtSN1 (Fig. 4) and an intergenic region of the 5S rDNA repeat (1003) (Hamilton et al. 2002; Herr et al. 2005). Corresponding to this absence of siRNAs, the AtSN1 DNA and the 5S rDNA were hypomethylated in the mutant (Hamilton et al. 2002; Herr et al. 2005) and, at the AtSN1 locus, there is $\mathrm{H} 3 \mathrm{~K} 4$ rather than $\mathrm{H} 3 \mathrm{~K} 9$ histone methylation (Zilberman et al. 2004). Other mutants affecting RdDM and siRNA production at AtSN1 include an RNA-dependent RNA polymerase RDR2, a Dicer DCL3, an Argonaute protein AGO4, and a DNA methyltransferase MET1 (Zilberman et al. 2003; Lippman et al. 2004; Xie et al. 2004).

The product of NRPDIa is a subunit of putative RNA polymerase (Pol) IV. Pol IV is structurally distinct from the conventional DNA-dependent RNA polymerases I-III and we have proposed that it is a silencing-specific polymerase (Herr et al. 2005). A likely scenario is that Pol IV transcripts are converted into a dsRNA form by RDR2 and that the dsRNA is then cleaved into 24-nucleotide siRNA by Dicer DCL3. By analogy with a similar chromatin silencing mechanism in fission yeast, the role of AGO4 is a likely component of an effector complex that is guided to AtSN1 and other target loci by the 24-nucleotide siRNAs. This effector complex would then mediate the DNA and histone H3K9 methylation. However, AtSN1 RNA levels are affected by ago 4 mutations (Zilberman et al. 2003) that would be expected to be downstream of siRNA production and by met1 (Lippman et al. 2004). To explain these findings it seems that, as has been proposed for RNA-mediated chromatin silencing in Saccharomyces pombe (Sugiyama et al. 2005), there is a self-reinforcing silencing pathway in which pol IV would be dependent on AGO4 and MET1. Correspondingly, AGO4 and MET1 would be dependent on pol IV (Fig. 5A).

At present it is not clear whether this Pol IV/RDR2/DCL3 pathway is the only mechanism for RdDM in plants. Mutant screens for loss of transgene 
Figure 5. Interactions in silencing pathways. (A) A self-reinforcing circular pathway of chromatin silencing in which AGO4 is required for a positive feedback loop that reinforces the basic silencing pathway involving pol IV/RDR2/DCL3-mediated siRNA synthesis. (B) An RNA silencing cycle in which the siRNA participates in both negative and positive feedback. The siRNA in a Slicer complex (AGO) degrades the ssRNA and slows down the cycle $(\mathrm{O})$. Alternatively, the siRNA can accelerate production of secondary RNA by priming RDR-mediated synthesis of dsRNA (O).

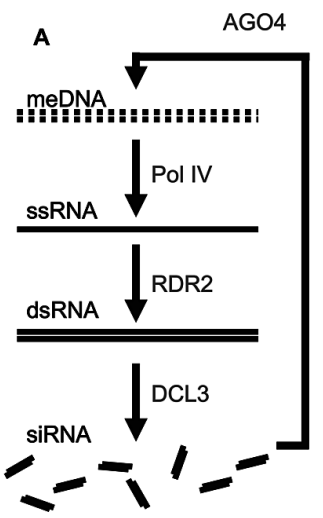

B

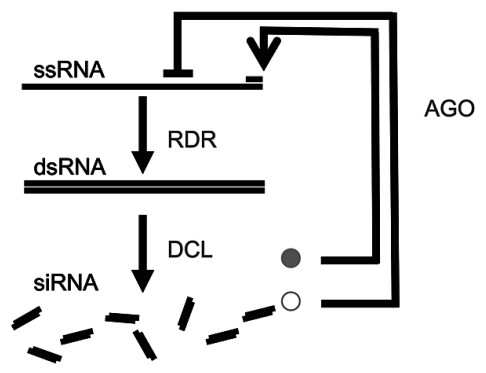

RdDM have revealed the involvement of a chromatin remodeling protein and a histone deacetylase that are not known to affect AtSN1 and other endogenous siRNAs (Aufsatz et al. 2002b; Kanno et al. 2004). Moreover, these screens have not so far produced mutants in any of the pol IV/RDR2/DCL3/AGO4 proteins described above. The only overlap with the endogenous siRNA-mediated chromatin pathway is DNA methyltransferases (Cao et al. 2003; Aufsatz et al. 2004). It is possible, therefore, that DNA methyltransferases are shared components in several RdDM pathways.

\section{SILENCING PATHWAYS}

There are at least three different RNA silencing pathways in plants in which dsRNA is processed into siRNA or miRNA. There are the miRNA and viral RNA pathways in which the targets are RNA that is silenced by turnover and/or an effect at the translational level. The third pathway is targeted to DNA and the end result is DNA methylation and heterochromatin formation (Baulcombe 2004). Equivalent pathways may operate in animals and fungi indicating that the diversity of silencing pathways may predate the evolutionary divergence of plants and animals.

In plants the diversity of silencing pathways is reflected in the existence of multigene families for silencing genes. For example, the Dicer DCL1 is required for miRNA silencing whereas DCL3 is implicated in the nuclear pathway (Xie et al. 2004). Similarly the RNA-dependent RNA polymerases RDR1 and RDR6 influence viral RNA silencing, whereas RDR2 is involved in the chromatin silencing pathway. There are ten AGO homologs encoded in the $A$. thaliana genome and at least some of them are indicators of diversity in silencing pathways. The function of AGO7 in A. thaliana, for example, is associated with RDR6 (Hunter et al. 2003), whereas AGO4 and AGO1 are involved in chromatin silencing and miRNA pathways (Zilberman et al. 2003; Vaucheret et al. 2004). It seems likely, by extrapolation, that at least some of the currently unassigned AGO functions could be associated with effector complexes of RNA silencing that are adapted to silence in specialized cells or at particular developmental stages.
These silencing pathways, particularly those with an RDR protein, may form self-reinforcing loops. The transient presence of even a small amount of siRNA in such a pathway could initiate a series of cycles leading eventually to an abundance of siRNAs and strong silencing of the target DNA or RNA (Fig. 3B). In effect, there would be positive feedback that, given the potential for systemic signaling, could lead to a gene being silenced throughout a plant as a result of a localized initiation event.

More complex feedback mechanisms might also operate because ssRNAs are both precursors and targets of siRNA. High levels of the ssRNA, for example, would initially provide an abundant RDR substrate and siRNA levels would increase (Figs. 2 and 4B). The ssRNA would then be targeted by Slicer (Fig. 4B) and its levels would decline. However, as the level of ssRNA decreases, there would be a knockon effect on RDR-mediated siRNA production. Eventually the Slicer activity against the ssRNA would be weakened. The ssRNA levels would then increase and the cycle would start again.

Feedback mechanisms also operate in the miRNA pathways because the mRNA transcripts encoding the Dicer enzyme DCL1 (Xie et al. 2003) and the AGO1 Slicer (Vaucheret et al. 2004) are themselves targets of miRNAs (miR162 and miR168, respectively). The resulting feedback mechanisms might explain the otherwise paradoxical increase in miRNAs in the presence of viral suppressors of silencing (Mallory et al. 2002; Chapman et al. 2004; Dunoyer et al. 2004): The suppression of silencing would uncouple the feedback loop so that the abundance of AGO1, DCL1, and the associated miRNAs would be unchecked by the normal mechanisms.

Further complexity may result from the potential of silencing pathways to interact. In some instances, as illustrated by a GFP transgene silencing phenotype in Arabidopsis inflorescences, the interaction is cooperative: GFP silencing requires the combined action of the RDR6 and the pol IV/RDR2 chromatin silencing pathways (Herr et al. 2005). There may also be an interaction between the miRNA and chromatin silencing pathways because the methylation of phabulosa DNA is reduced if there is a mutation in a miRNA target sequence (miR167) (Bao et al. 2004).

There is also the potential for antagonism between si- 
lencing pathways. It is possible, for example, to ablate the posttranscriptional silencing capability of a gene by targeting transcriptional silencing to a promoter (Hamilton and Baulcombe 1999). This type of antagonism between transcriptional and posttranscriptional RNA silencing may explain the lateral shoots with pigmented flowers that sometimes appear on CS-cosuppressed plants (Jorgensen et al. 1995): It could be that the CS silencer transgene has become transcriptionally silenced and so has lost the capability to produce siRNAs that target the endogenous CS RNA.

The biological consequence of these various interactions will vary depending on the nature of the silencing pathway and possibly on the target sequence. An RNA or DNA target that is more accessible to an siRNA or miRNA, for example, will contribute to feedback loops more actively than an inaccessible target. To unravel the significance of the silencing pathway interactions requires better understanding of RNA silencing mechanisms and of their biological roles. Until now, the only work on the biological role of silencing pathways in plants has involved virus susceptibility, miRNAs affecting gene expression in growth and development (Bartel 2004), and some recent analyses of trans-acting siRNAs (Peragine et al. 2004; Vazquez et al. 2004).

\section{ACKNOWLEDGMENTS}

We are grateful to the Gatsby Charitable Foundation and the Biotechnology and Biological Sciences Research Council for supporting research in my laboratory. A.J.H. acknowledges a fellowship from the Burroughs Wellcome Fund.

\section{REFERENCES}

Allen E., Xie Z., Gustafson A.M., Sung G.-H., Spatafora J.W., and Carrington J.C. 2004. Evolution of microRNA genes by inverted duplication of target gene sequences in Arabidopsis thaliana. Nat. Genet. 36: 1282.

Anandalakshmi R., Pruss G.J., Ge X., Marathe R., Smith T.H., and Vance V.B. 1998. A viral suppressor of gene silencing in plants. Proc. Natl. Acad. Sci. 95: 13079.

Aufsatz W., Mette M.F., Matzke A.J.M., and Matzke M. 2004. The role of MET1 in RNA-directed de novo and maintenance methylation of CG dinucleotides. Plant Mol. Biol. 54: 793.

Aufsatz W., Mette M.F., van der Winden J., Matzke A.J.M., and Matzke M. 2002a. RNA-directed DNA methylation in Arabidopsis. Proc. Natl. Acad. Sci. 99: 16499.

Aufsatz W., Mette M.F., van der Winden J., Matzke M., and Matzke A.J.M. 2002b. HDA6, a putative histone deacetylase needed to enhance DNA methylation induced by doublestranded RNA. EMBO J. 21: 6832.

Bao N., Lye K.-W., and Barton M.K. 2004. MicroRNA binding sites in Arabidopsis class III HD-ZIP mRNAs are required for methylation of the template chromosome. Dev. Cell 7: 653

Bartel D.P. 2004. MicroRNAs: Genomics, biogenesis, mechanism, and function. Cell 116: 281.

Baulcombe D. 2004. RNA silencing in plants. Nature 431: 356.

Brigneti G., Voinnet O., Li W.X., Ji L.H., Ding S.W., and Baulcombe D.C. 1998. Viral pathogenicity determinants are suppressors of transgene silencing in Nicotiana benthamiana. EMBO J. 17: 6739.

Cao X., Aufsatz W., Zilberman D., Mette M.F., Huang M.S., Matzke M., and Jacobsen S.E. 2003. Role of the DRM and
CMT3 methyltransferases in RNA-directed DNA methylation. Curr. Biol. 13: 2212.

Chapman E.J., Prokhnevsky A.I., Gopinath K., Dolja V., and Carrington J.C. 2004. Viral RNA silencing suppressors inhibit the microRNA pathway at an intermediate step. Genes Dev. 18: 1179.

Cogoni C. and Macino G. 1999. Gene silencing in Neurospora crassa requires a protein homologous to RNA-dependent RNA polymerase. Nature 399: 166.

Covey S.N., Al-Kaff N.S., Langara A., and Turner D.S. 1997. Plants combat infection by gene silencing. Nature 385: 781 .

Dalmay T., Hamilton A.J., Rudd S., Angell S., and Baulcombe D.C. 2000. An RNA-dependent RNA polymerase gene in Arabidopsis is required for posttranscriptional gene silencing mediated by a transgene but not by a virus. Cell 101: 543 .

Dunoyer P., Lecellier C.H., Parizotto E.A., Himber C., and Voinnet O. 2004. Probing the microRNA and small interfering RNA pathways with virus-encoded suppressors of RNA silencing. Plant Cell 16: 1235.

Feinberg E.H. and Hunter C.P. 2003. Transport of dsRNA into cells by the transmembrane protein SID-1. Science 301: 1545.

Gazzani S., Lawrenson T., Woodward C., Headon D., and Sablowski R. 2004. A link between mRNA turnover and RNA interference in Arabidopsis. Science 306: 1046.

Hamilton A.J. and Baulcombe D.C. 1999. A species of small antisense RNA in post-transcriptional gene silencing in plants. Science 286: 950.

Hamilton A.J., Voinnet O., Chappell L., and Baulcombe D.C. 2002. Two classes of short interfering RNA in RNA silencing. EMBO J. 21: 4671.

Haywood V., Kragler F., and Lucas W.J. 2002. Plasmodesmata: Pathways for protein and ribonucleoprotein signaling. Plant Cell 14: S303.

Herr A.J., Jensen M.B., Dalmay T., and Baulcombe D.C. 2005. RNA polymerase IV directs silencing of endogenous DNA. Science (in press).

Himber C., Dunoyer P., Moissiard G., Ritzenthaler C., and Voinnet O. 2003. Transitivity-dependent and -independent cell-tocell movement of RNA silencing. EMBO J. 22: 4523.

Hunter C., Sun H., and Poethig R.S. 2003. The Arabidopsis heterochronic gene ZIPPY is an ARGONAUTE family member. Curr. Biol. 13: 1734.

Iyer L.M., Koonin E.V., and Aravind L. 2003. Evolutionary connection between the catalytic subunits of DNA-dependent RNA polymerases and eukaryotic RNA-dependent RNA polymerases and the origin of RNA polymerases. BMC Struct. Biol. 3: 1. (http://www.biomedcentral.com/1472$6807 / 3 / 1)$

Jones L., Hamilton A.J., Voinnet O., Thomas C.L., Maule A.J., and Baulcombe D.C. 1999. RNA-DNA interactions and DNA methylation in post-transcriptional gene silencing. Plant Cell 11: 2291

Jones-Rhoades M.W. and Bartel D.P. 2004. Computational identification of plant MicroRNAs and their targets, including a stress-induced miRNA. Mol. Cell 14: 787.

Jorgensen R.A., Que Q.D., English J.J., Cluster P., and Napoli C. 1995. Sense-suppression of flower color genes as a sensitive reporter of epigenetic states of gene-expression in plant development. Plant Physiol. 108: 14.

Kanno T., Mette F., Kreil D.P., Aufsatz W., Matzke A.J.M., and Matzke M. 2004. Involvement of putative SNF2 chromatin remodelling protein DRD1 in RNA-directred DNA methylation. Curr. Biol. 14: 801.

Kasschau K.D. and Carrington J.C. 1998. A counterdefensive strategy of plant viruses: Suppression of post-transcriptional gene silencing. Cell 95: 461.

Li H., Li W.X., and Ding S.W. 2002. Induction and suppression of RNA silencing by an animal virus. Science 296: 1319.

Li W.-X., Li H., Lu R., Li F., Dus M., Atkinson P., Brydon E.W.A., Johnson K.L., Garcia-Sastre A., Ball L.A., Palease P., and Ding S.-W. 2004. Interferon antagonist proteins of influenza and vaccinia virus are suppressors of RNA silencing. Proc. Natl. Acad. Sci. 101: 1350.

Lichner Z., Silhavy D., and Burgyan J. 2003. Double-stranded 
RNA-binding proteins could suppress RNA interference-mediated antiviral defences. J. Gen. Virol. 84: 975.

Lindbo J.A., Silva-Rosales L., Proebsting W.M., and Dougherty W.G. 1993. Induction of a highly specific antiviral state in transgenic plants: Implications for regulation of gene expression and virus resistance. Plant Cell 5: 1749.

Lippman Z., May B., Yordan C., Singer T., and Martienssen R. 2004. Distinct mechanisms determine transposon inheritance and methylation via small interfering RNA and histone modification. PLoS Biol. 1: 420.

Liu J., Carmell M.A., Rivas F.V., Marsden C.G., Thomson M., Song J.J., Hammond S.M., Joshua-Tor L., and Hannon G.J. 2004. Argonaute 2 is the catalytic engine of mammalian RNAi. Science 305: 1437.

Longstaff M., Brigneti G., Boccard F., Chapman S.N., and Baulcombe D.C. 1993. Extreme resistance to potato virus X infection in plants expressing a modified component of the putative viral replicase. EMBO J. 12: 379 .

Ma J.B., Ye K.Q., and Patel D.J. 2004. Structural basis for overhang-specific small interfering RNA recognition by the PAZ domain. Nature 429: 318.

Makeyev E.V. and Bamford D.H. 2002. Cellular RNA-dependent RNA polymerase involved in posttranscriptional gene silencing has two distinct activity modes. Mol. Cell 10: 1417.

Mallory A.C., Reinhart B.J., Bartel D., Vance V.B., and Bowman L.H. 2002. A viral suppressor of RNA silencing differentially regulates the accumulation of short interfering RNAs and microRNAs in tobacco. Proc. Natl. Acad. Sci. 99: 15228.

Mathieu O. and Bender J. 2004. RNA-directed DNA methylation. J. Cell Sci. 117: 4881.

Meister G., Landthaler M., Patkaniowska A., Dorsett Y., Teng G., and Tuschl T. 2004. Human Argonaute2 mediates RNA cleavage targeted by miRNAs and siRNAs. Mol. Cell 15: 185 .

Mette M.F., Aufsatz W., van der Winden J., Matzke M.A., and Matzke A.J.M. 2000. Transcriptional silencing and promoter methylation triggered by double-stranded RNA. EMBOJ. 19: 5194.

Mourrain P., Beclin C., Elmayan T., Feuerbach F., Godon C., Morel J.-B., Jouette D., Lacombe A.M., Nikic S., Picault N., Remoue K., Sanial M., Vo T.A., and Vaucheret H. 2000. Arabidopsis $S G S 2$ and $S G S 3$ genes are required for posttranscriptional gene silencing and natural virus resistance. Cell 101: 533 .

Napoli C., Lemieux C., and Jorgensen R.A. 1990. Introduction of a chimeric chalcone synthase gene into petunia results in reversible co-suppression of homologous genes in trans. Plant Cell 2: 279.

Palauqui J.C., Elmayan T., Pollien J.M., and Vaucheret H. 1997. Systemic acquired silencing: Transgene-specific post-transcriptional silencing is transmitted by grafting from silenced stocks to non-silenced scions. EMBO J. 16: 4738.

Peragine A., Yoshikawa M., Wu G., Albrecht H.L., and Poethig R.S. 2004. SGS3 and SGS2/SDE1/RDR6 are required for juvenile development and the production of trans-acting siRNAs in Arabidopsis. Genes Dev. 18: 2368.

Pfeffer S., Zavolan M., Grasser F.A., Chien M., Russo J.J., Ju J., John B., Enright A.J., Marks D.S., Sander C., and Tuschl T. 2004. Identification of virus-encoded MicroRNAs. Science 304: 734 .

Rand T.A., Ginalski K., Grishin N.V., and Wang X. 2004. Biochemical identification of Argonaute 2 as the sole protein required for RNA-induced silencing complex activity. Proc. Natl. Acad. Sci. 101: 14385.

Ratcliff F., Harrison B.D., and Baulcombe D.C. 1997. A similarity between viral defense and gene silencing in plants. Science 276: 1558.

Ruiz M.T., Voinnet O., and Baulcombe D.C. 1998. Initiation and maintenance of virus-induced gene silencing. Plant Cell 10: 937.

Sachs A.B. and Varani G. 2000. Eukaryotic translation initiation: There are (at least) two sides to every story. Nat. Struct. Biol. 7: 356.

Schiebel W., Haas B., Marinkovic S., Klanner A., and Sanger H.L. 1993. RNA-directed RNA polymerase from tomato leaves. II. Catalytic in vitro properties. J. Biol. Chem. 268:
11858

Sijen T., Fleenor J., Simmer F., Thijssen K.L., Parrish S., Timmons L., Plasterk R.H.A., and Fire A. 2001. On the role of RNA amplification in dsRNA-triggered gene silencing. Cell 107: 465 .

Smardon A., Spoerke J.M., Stacey S.C., Klein M.E., Mackin N., and Maine E.M. 2000. EGO-1 is related to RNA-directed RNA polymerase and functions in germ-line development and RNA interference in C. elegans. Curr. Biol. 10: 169.

Song J.J., Liu J., Tolia N.H., Schneiderman J., Smith S.K., Martienssen R.A., Hannon G.J., and Joshua-Tor L. 2003. The crystal structure of the Argonaute2 PAZ domain reveals an RNA binding motif in RNAi effector complexes. Nat. Struct. Biol. 10: 1026.

Stam M., de Bruin R., van Blokland R., van der Hoorn R.A.L., Mol J.N.M., and Kooter J.M. 2000. Distinct features of posttranscriptional gene silencing by antisense transgenes in single copy and inverted T-DNA repeat loci. Plant J. 21: 27.

Sugiyama T., Cam H., Verdel A., Moazed D., and Grewal S.I.S 2005. RNA-dependent RNA polymerase is an essential component of a self-enforcing loop coupling heterochromatin assembly to siRNA production. Proc. Natl. Acad. Sci. 102: 152.

Tang G., Reinhart B.J., Bartel D., and Zamore P.D. 2002. A biochemical framework for RNA silencing in plants. Genes Dev. 17: 49 .

Vaistij F.E., Jones L., and Baulcombe D.C. 2002. Spreading of RNA targeting and DNA methylation in RNA silencing requires transcription of the target gene and a putative RNA-dependent RNA polymerase. Plant Cell 14: 857.

van Blokland R., Van der Geest N., Mol J.N.M., and Kooter J.M 1994. Transgene-mediated suppression of chalcone synthase expression in Petunia hybrida results from an increase in RNA turnover. Plant J. 6: 861 .

van der Krol A.R., Mur L.A., Beld M., Mol J.N.M., and Stuitje A.R. 1990. Flavonoid genes in petunia: Addition of a limited number of gene copies may lead to a suppression of gene expression. Plant Cell 2: 291.

Vaucheret H., Vazquez F., Crete P., and Bartel D.P. 2004. The action of ARGONAUTE1 in the miRNA pathway and its regulation by the miRNA pathway are crucial for plant development. Genes Dev. 18: 1187.

Vazquez F., Vaucheret H., Rajagopalan R., Lepers C., Gasciolli V., Mallory A.C., Hilbert J.-L., Bartel D.P., and Crete P. 2004. Endogenous trans-acting siRNAs regulate the accumulation of Arabidopsis mRNAs. Mol. Cell 16: 69.

Voinnet O. and Baulcombe D.C. 1997. Systemic signalling in gene silencing. Nature 389: 553.

Voinnet O., Lederer C., and Baulcombe D.C. 2000. A viral movement protein prevents spread of the gene silencing signal in Nicotiana benthamiana. Cell 103: 157.

Voinnet O., Vain P., Angell S., and Baulcombe D.C. 1998. Systemic spread of sequence-specific transgene RNA degradation is initiated by localised introduction of ectopic promoterless DNA. Cell 95: 177.

Volpe T., Kidner C., Hall I.M., Teng G., Grewal S.I.S., and Martienssen R. 2002. Regulation of heterochromatic silencing and histone H3 lysine-9 methylation by RNAi. Science 297: 1833.

Wassenegger M., Heimes S., Riedel L., and Sanger H.L. 1994. RNA-directed de novo methylation of genomic sequences in plants. Cell 76: 567.

Wingard S.A. 1928. Hosts and symptoms of ring spot, a virus disease of plants. J. Agric. Res. 37: 127.

Xie Z., Kasschau K.D., and Carrington J.C. 2003. Negative feedback regulation of Dicer-Likel in Arabidopsis by microRNAguided mRNA degradation. Curr. Biol. 13: 784.

Xie Z., Fan B., Chen C.H., and Chen Z. 2001. An important role of an inducible RNA-dependent RNA polymerase in plant antiviral defense. Proc. Natl. Acad. Sci. 98: 6516.

Xie Z., Johansen L.K., Gustafson A.M., Kasschau K.D., Lellis A.D., Zilberman D., Jacobsen S.E., and Carrington J.C. 2004. Genetic and functional diversification of small RNA pathways in plants. PLoS Biol. 2: E104.

Yamada K., Lim J., Dale J.M., Chen H., Shinn P., Palm C.J., 
Southwick A.M., Wu H.C., Kim C., Nguyen M., Pham P., Cheuk R., Karlin-Newmann G., Liu S.X., Lam B., Sakano H., Wu T., Yu G., Miranda M., Quach H.L., Tripp M., Chang C.H., Lee J.M., Toriumi M., Chan M.M., et al. 2003. Empirical analysis of transcriptional activity in the Arabidopsis genome. Science 302: 842.

Yan K.S., Yan S., Farooq A., Han A., Zeng L., and Zhou M.M. 2003. Structure and conserved RNA binding of the PAZ do- main. Nature 426: 468.

Zilberman D., Cao X., and Jacobsen S.E. 2003. ARGONAUTE4 control of locus specific siRNA accumulation and DNA and histone methylation. Science 299: 716.

Zilberman D., Cao X., Johansen L.K., Xie Z., Carrington J.C., and Jacobsen S.E. 2004. Role of Arabidopsis ARGONAUTE4 in RNA-directed DNA methylation triggered by inverted repeats. Curr. Biol. 14: 1214. 


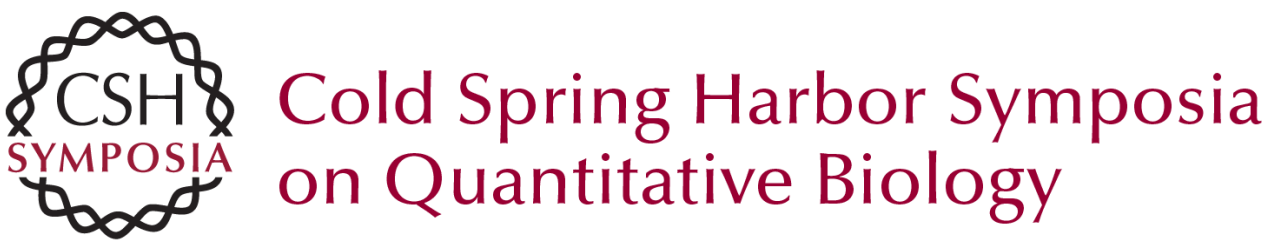

\title{
RNA Silencing Pathways in Plants
}

\author{
A.J. HERR and D.C. BAULCOMBE
}

Cold Spring Harb Symp Quant Biol 2004 69: 363-370

Access the most recent version at doi:10.1101/sqb.2004.69.363

References This article cites 75 articles, 36 of which can be accessed free at: http://symposium.cshlp.org/content/69/363.full.html\#ref-list-1

\section{License}

Email Alerting Receive free email alerts when new articles cite this article - sign up in Service the box at the top right corner of the article or click here. 